\title{
Correspondence
}

To the Editors:

\section{Is acupuncture harmless?}

Sri Lanka Journal of Child Health, 2002; 31: 99

A 7 year old girl from Mutwal was admitted to our unit recently with status epilepticus and died within 24 hours of admission despite intensive treatment. She was a mentally retarded child who had seizures from the age of 5 months and had been followed up in another medical clinic at Lady Ridgeway Hospital, Colombo. Her seizures had been under control with proper anticonvulsant therapy.

About 18 months ago the parents had decided to seek acupuncture treatment and the anticonvulsants had been omitted. No clinic visits had been made thereafter. The child, on and off, used to get fits at home which lasted a few minutes and subsided spontaneously. When the seizures recurred, on this occasion, the parents thought it would subside on its own; but, as the seizures continued, the relatives rushed the child to Lady Ridgeway Hospital, 4 hours after the onset of seizures.
Patients, who resort to alternative forms of medicine for such ailments, usually admit them to our hospitals whenever there is an emergency. Perhaps practitioners of alternative forms of medicine are probably not made aware of or are unaware of such admissions and deaths.

On our part, it is our duty to counsel the parents of children with chronic ailments, such as epilepsy or bronchial asthma, that poor compliance with allopathic medications, whilst on other forms of therapy, may result in a tragic ending.

Prof. Sanath P Lamabadusuriya Senior Professor of Paediatrics

Faculty of Medicine, University of Colombo 
